\title{
A INDÚSTRIA CRIATIVA E VÍNCULOS EMPREGATÍCIOS NO ESTADO DO RIO GRANDE DO SUL COMPORTAMENTO NOS ANOS DE 2010 E 2011
}

\author{
Judite Sanson BEM ${ }^{1}$ \\ Moisés WAISMANN ${ }^{2}$
}

\begin{abstract}
${ }^{1}$ Possui Graduação em Ciências Econômicas pela Universidade Federal do Rio Grande do Sul (1985) , Mestrado em Economia Rural pela Universidade Federal do Rio Grande do Sul (1992), Doutorado em História Íbero Americana pela Pontifícia Universidade Católica do Rio Grande do Sul (2001) ,e Pós Doutorado em economia da cultura pela Universidade Federal do RS ( 2014). Atualmente é Professora da Universidade de Caxias do Sul, Coordenadora do Curso de Ciências Econômicas do Centro Universitário La Salle - UNILASALLE, e Professora do Mestrado Profissional em Memória Social e Bens Culturais do UNILASALLE. Membro de corpo editorial do Jornal Contexto Econômico . Tem experiência na área de Economia , com ênfase em Crescimento, Economia do Meio Ambiente; Economia do Bem-Estar Social. Responsável pelo estudo e desenvolvimento da análise econômica do COREDE SinosRS. Atua principalmente nos seguintes temas: Economia da Cultura, Indústrias Criativas, Desenvolvimento Regional e Urbano. Economia do Trabalho. jsanson@ @erra.com.br

${ }^{2}$ Doutor em Educação no Programa de Pós-Graduação em Educação da Universidade do Vale do Rio dos Sinos (2013). Mestre em Agronegócios pelo Programa de Pós-Graduação em Agronegócios da Universidade Federal do Rio Grande do Sul (2002). Graduado em Ciências Econômicas pela UFRGS (1990). Professor-pesquisador da linha de pesquisa em Memória e Gestão Cultural do Mestrado em Memória Social e Bens Culturais do Centro Universitário La Salle (Unilasalle) e do grupo de pesquisa de Estratégias Regionais. Coordenador do Observatório Unilasalle: Trabalho, Gestão e Politicas Públicas. Investiga assuntos relacionados ao mercado de trabalho, a economia da educação, ao ensino superior, as políticas públicas, a economia da cultua, a cultura e a economia criativa. moises.waismann@bol.com.br
\end{abstract}

Recebido em: 23/05/2014 - Aprovado em: 30/06/2014 - Disponibilizado em: 30/07/2014

\begin{abstract}
Resumo
O termo indústria criativa surge na década de 1990 quando os Estados percebem que a Economia entrou na Era da Informação e que os ramos mais tradicionais da indústria estavam perdendo participação na geração de emprego e renda. Entre os ramos ou atividades criativas estão algumas nucleares, como as artes cênicas, design, outras mais periféricas como o vestuário. O Estado do Rio Grande do Sul tem como característica produtiva o agronegócio, mas têm procurado outras fontes produtivas como os diferentes segmentos da indústria criativa. Utilizando-se da nomenclatura internacional sobre o tema e dos dados do MTE o objetivo deste trabalho é mostrar o comportamento das ocupações nos diferentes segmentos da indústria criativa nos anos de 2010 e 2011. Observa-se que embora tenham crescido, entre 2010 e 2011, ainda é incipiente sua participação no total do emprego gaúcho e demanda um esforço sobremaneira para que outras carreiras que não as tradicionais sejam incorporadas às atividades produtivas de renome no contexto econômico e empresarial.
\end{abstract}

Palavras-Chave: Indústria Criativa, vínculos empregatícios, Estado do Rio Grande do Sul.

\begin{abstract}
The term creative industry emerges in the 1990s when states realize that the economy entered the Information Age and the more traditional branches of industry were losing interest in the generation of employment and income. Between branches or creative activities are some nuclear as the performing arts, design, other more peripheral as clothing. The state of Rio Grande do Sul has the characteristic productive agribusiness, but demand has other productive sources as the different segments of the creative industry. By using the international nomenclature on the subject and MTE data the aim of this work is to show the behavior of the occupations in the different segments of the creative industry in the years 2010 and 2011. It is observed that although they have grown between 2010 and 2011, is still incipient their share in total employment and the Gaucho demands an effort enormously to other careers than traditional productive activities are incorporated in reputed economic and business context.
\end{abstract}

Keywords: Creative Industry, employment contracts, State of Rio Grande do Sul. 


\section{Introdução}

As indústrias criativas compreendem, de acordo com Henry e Bruin (2011, p. 10) "those activities wich have their origin in individual creativity, skill and talent, and wich have a potential for wealth and job creation through the generation and exploitation of intellectual property”. Assim, os setores e subsetores que fazem parte destas atividades estão divididos em: um núcleo central ou "core", atividades relacionadas e atividades de apoio.

Isto posto, esta divisão estrutural carrega em si ocupações ou atividades profissionais que desenvolvem produtos mais ou menos elaborados. Mas há questões que ainda não puderam ser resolvidas de forma integral o que é um emprego criativo e qual a diferença entre um bem artístico e um bem industrial?

As ocupações das indústrias criativas, na qual o produto ou serviço contém um substancial elemento artístico ou esforço criativo, tem recebido uma maior atenção por parte de diferentes profissionais, entre eles economistas e administradores, pois os efeitos destas ocupações são importantes no mercado de trabalho.

O objetivo deste artigo será responder a primeira indagação, mediante o uso de diferentes definições, sobre o que são e como se dividem as atividades criativas.
Posteriormente, através do emprego da divisão do Ministério do Trabalho e Emprego - MTE, classificar os vínculos da indústria criativa, através dos CNAE, no Estado do Rio Grande do Sul, Brasil, em 2010 e 2011.

\section{Conceituando Indústria Criativa}

De acordo com Sancho, Gracia e Prieto (2005) a maior parte dos economistas, sobretudo as escolas de Adam Smith e Karl Marx, durante os últimos séculos, julgou que a cultura era improdutiva e, portanto, irrelevante. Mas alguns economistas romperam este círculo, entre eles Robbins e Keynes, mas nenhum dos dois estudou a cultura de forma econômica, ou seja, utilizouse de ferramentas ou instrumentais econômicos para tal.

Assim, as ligações entre a economia e a cultura, até meados da década de 1960, ou eram desconsideradas ou consideradas com certa descrença. Naquele momento o Estado exercia o principal papel nas discussões, sendo as artes e a cultura secundárias nas discussões. Ainda não era percebido seu significado econômico para o desenvolvimento de uma região, bem como a geração de emprego e renda que de suas atividades derivavam. Esta era considerada mais como parte da política social do que atividade sujeita a critérios econômicos.

No entanto nos anos de 1970/80 passou-se a explorar melhor as relações entre 
economia, cultura, emprego, renda. Novamente cabe destacar que sempre houve consciência desta relação, mas a partir deste período o enfoque da criatividade, e das profissões no desenvolvimento de valores agregados, passou a ser explorado. Cabe ainda lembrar que até hoje, em pleno século XXI, ainda é difícil quantificar estas relações entre atividades profissionais, criatividade e valor adicionado, pois o vínculo empregatício não é sinônimo de criatividade, mas a formação profissional pode corresponder a uma contribuição positiva à geração de produtos com maior valor agregado.

A criatividade é fonte de geração de valor e é inata ao ser humano. Todo o esforço produtivo torna-se importante, pois além da valorização das potencialidades existentes proporciona o desenvolvimento do indivíduo como ser produtivo. Não é por menos que desde a escola Clássica discute-se o trabalho como fonte de valor. É do trabalho que surge a riqueza de uma sociedade e produzidos os bens e serviços para às diferentes finalidades: produção e consumo de primeira e necessidades secundárias, bem como aqueles destinados à cultura do ser humano.

Entre os empregos produtivos estão àqueles relacionados às indústrias criativas. $\mathrm{O}$ interesse pelas indústrias criativas aparece à medida que há uma reflexão, nos anos de 1990, sobre formas alternativas de crescimento econômico, e com isto a valorização crescente de determinadas atividades que fazem parte da esfera cultural. Mais que atividades produtivas, sejam nucleares, periféricas ou de apoio, estas são responsáveis pelo emprego, geram renda, exportações, impostos, um grande elo ou cadeia, que são ou tem na criatividade o eixo central de sua existência.

Quadro 1. Semelhanças e diferenças entre conceitos das indústrias na área da cultura

\begin{tabular}{|c|c|c|}
\hline & Definiçãa & Setores envolvidos \\
\hline Uี & $\begin{array}{l}\text { Caracterizadas } \\
\text { amplamente pela } \\
\text { natureza dos insumos } \\
\text { de trabalho: } \\
\text { "indivíduos criativos" }\end{array}$ & $\begin{array}{l}\text { Propaganda, } \\
\text { Arquitetura, Design, } \\
\text { Software interativo, } \\
\text { Filme e TV, Música, } \\
\text { Publicações, Artes } \\
\text { performáticas. }\end{array}$ \\
\hline 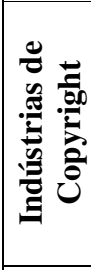 & $\begin{array}{l}\text { Definidas pela } \\
\text { natureza das receitas e } \\
\text { pela produção da } \\
\text { indústria }\end{array}$ & $\begin{array}{l}\text { Arte comercial, Artes } \\
\text { criativas, Filmes e } \\
\text { vídeos, Música, } \\
\text { Publicação, Mídia de } \\
\text { gravação, Software de } \\
\text { processamento de } \\
\text { dados. }\end{array}$ \\
\hline 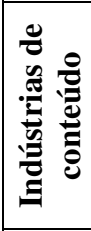 & $\begin{array}{l}\text { Definidas pelo foco na } \\
\text { produção industrial }\end{array}$ & $\begin{array}{l}\text { Música pré-gravada, } \\
\text { Música gravada, } \\
\text { Música de varejo, } \\
\text { Broadcasting e filmes, } \\
\text { Software, Serviços de } \\
\text { multimídia. }\end{array}$ \\
\hline 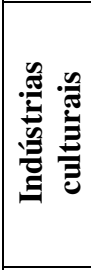 & $\begin{array}{l}\text { Definidas em função } \\
\text { do objeto cultural }\end{array}$ & $\begin{array}{l}\text { Museus e galerias, } \\
\text { Artes visuais e } \\
\text { artesanato, Educação } \\
\text { de artes, Broadcasting } \\
\text { e filmes, Música, } \\
\text { Artes performáticas, } \\
\text { Literatura, Livrarias. }\end{array}$ \\
\hline 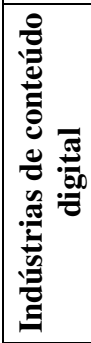 & $\begin{array}{lr}\text { Definidas } & \text { pela } \\
\text { combinação } & \text { de } \\
\text { tecnologia e pelo foco } \\
\text { na produção } \\
\text { indústria }\end{array}$ & \begin{tabular}{lr}
\multicolumn{3}{l}{ Arte comercial, Filme } \\
e vídeo, Fotografia, \\
Jogos eletrônicos, \\
Mídia de gravação, \\
Gravação de som, \\
Sistemas & de \\
armazenamento & $\mathrm{e}$ \\
recuperação & de \\
informações. &
\end{tabular} \\
\hline
\end{tabular}

Fonte: Hartley, 2005, p.30

O quadro 01 apresenta diferentes conceitos sobre indústrias na área cultural e as características que as distingue. O termo 
indústria cultural está associado à Escola de Frankfurt (Dentre os pensadores desta Escola, citam-se Theodor Adorno, Max Horkheimer, Hebert Marcuse, Erich Fromm e Walter Benjamin). Os dois primeiros autores, Adorno e Horkheimer, foram os criadores de um conceito base para os estudos da indústria cultural. No entanto, com o passar das décadas, em 1990 surge o conceito de indústria criativa, apontando para uma ampliação dos domínios da cultura, entre eles atividades como a moda, design, arquitetura, entre outros.

A partir dos ano de 1990, sobretudo na Europa, ganha força a ideia de a indústrias criativas, sendo dois documentos importantes nesta evolução: o primeiro de 1998 e o posterior de 2001 do DCMS intitulados Creative Industries Mapping Document, que as definiu como "[...] aquelas indústrias que têm sua origem na criatividade indivídual, habilidade e talento e que têm um potencial de geração de riqueza e criação de emprego através da exploração da propriedade privada". (DCMS, 2012)

\section{A UNCTAD (2011) propõe uma} definição que entende as indústrias como uma cadeia, sendo composta de três grandes áreas. Em primeiro lugar, tem-se o que se denominou de núcleo da indústria que inclui os segmentos de Expressões Culturais, Artes Cênicas, Artes Visuais, Música, Filme \& Vídeo, TV \& Rádio, Mercado Editorial,
Software \& Computação, Arquitetura, Design, Moda e Publicidade. Assim o núcleo é composto, essencialmente, de serviços, que têm a atividade criativa como parte principal do processo produtivo. Em seguida, encontram-se as áreas relacionadas, envolvendo segmentos de provisão direta de bens e serviços ao núcleo e compostos em grande parte por indústrias e empresas de serviços fornecedoras de materiais e elementos fundamentais para o funcionamento do núcleo. Finalmente, observou-se que a cadeia é composta de um terceiro grupo de atividades, de provisão de bens e serviços de forma mais indireta, chamada de atividades de apoio.

Para a UNESCO (2013, p. 3)

\begin{abstract}
O termo indústrias culturais prazo refere-se às indústrias que combinam a criação, produção e comercialização de conteúdos criativos, que são intangíveis e de natureza cultural. Os conteúdos são tipicamente protegidos por direitos autorais e eles podem assumir a forma de um bem ou de um serviço. Em geral, as Indústrias culturais incluem impressão, publicação e multimídia, audiovisual, fonográfica e produções cinematográficas, bem como artesanato e design. O termo indústrias criativas abrange uma ampla gama de atividades que incluem as indústrias culturais, além de toda produção cultural ou artística, seja ao vivo ou produzido como uma unidade individual. As indústrias criativas são aquelas em que o produto ou serviço contém um elemento substancial de esforço artístico ou criativo e incluem atividades como a arquitetura e publicidade. [...] estes termos [...] não são sinônimos [...].
\end{abstract}

Assim, "o valor das indústrias criativas não está confinado à atividade econômica como tal, mas se entende também 
a novos modelos de desenvolvimento [...]" ( HARTLEY, 2005, p.3)

O desenvolvimento, neste novo sentido, aplica especial atenção ao papel da educação como proporcionadora de conhecimentos individuais que serão transmitidos ao processo produtivo, pois "Nossos dias estão sendo arrastados por uma avalanche de inovações na ciência, tecnologia e pensamento social." Assim, faz-se crescente o conhecimento para exercê-los em atividades cada vez mais inovadoras. (HARTLEY, 2005, p.3)

Assim, a próxima sessão procura mostrar a relação entre os vínculos de trabalho nas indústrias criativas e a educação formal destes.

\section{A análise dos vínculos empregatícios na indústria criativa do Rio Grande do Sul em 2010 e 2011.}

O mercado de trabalho das atividades que compreendem a indústria criativa apresenta características e entre elas pode-se citar uma: "[...] creative workers spend tremendous amounts of time and money on education.” A educação é a porta de entrada básica, é um up na carreira, aprendizagem contínua e atualização de conhecimentos. Isto é tão mais vizível "[...] for workers in rapidly changing high-technology fields" (FLORIDA, 2002, p. 114)

Os trabalhadores, desta forma, vêm aumentando seus patamares de educação e as aspirações no exercício de suas atividades produtivas, ao mesmo tempo em que o trabalho passa a ser central na vida dos indivíduos. Assim os indivíduos passam a ser profissionais "organizacionais" e parte do seu prazer/dor é a criatividade/jornada de trabalho.

Esta relação existente entre educação e emprego é relevante à medida que se aceita como válida a teoria do capital humano a qual atribui à educação papel fundamental no desenvolvimento regional e na produtividade do trabalhador. A Teoria do Capital Humano afirma que uma maior escolarização contribui, diretamente, para a melhoria da qualidade de vida dos indivíduos, em função de um aumento de renda que decorre da sua melhor qualificação para o desempenho no mercado de trabalho. Em outras palavras, o incremento da produtividade - proveniente do aumento da capacitação - levaria a que o indivíduo também se beneficiasse pelo aumento dos seus salários. Hoje já se percebe que não necessariamente a educação proporciona um aumento de bem-estar, pois não garante, obrigatoriamente, acesso a melhores empregos, mas não se pode contradizer que uma pessoa que sabe ler, escrever e realizar as quatro operações é mais produtiva do que aquela que apenas sabe "rabiscar o seu nome".

Assim, partindo do principio que as atividades criativas têm como insumos a criatividade e a qualificação profissional 
estuda-se o comportamento dos vínculos nas indústrias criativas.

As informações sobre mercado de trabalho correspondem ao mercado formal, pois os dados do mercado informal não são dispostos pelas bases de dados oficiais. No entanto, não se pode desprezar que o mercado informal, em qualquer atividade, é importante dado o número de pessoas ocupas nestas atividades, dos impostos não recolhidos, entre outros. A técnica de análise dos dados aqui utilizada é de natureza quantitativa, baseada no banco de dados da Relação Anual de Informações Sociais (RAIS), disponibilizada pelo Ministério do Trabalho e Emprego (MTE) por meio do Programa de Disseminação de Estatísticas do Trabalho (PDET).

Tabela 1 - Quantidade, proporção e variação (base 100 = 2010) de vínculos profissionais no segmento da Indústria Criativa, em outros segmentos econômicos e no total de segmentos econômicos nos ano de 2010 e 2011 no estado do Rio Grande do Sul.

\begin{tabular}{l|r|r|r}
\hline & $\begin{array}{c}\text { Indústria } \\
\text { Criativa }\end{array}$ & $\begin{array}{c}\text { Outros } \\
\text { segmentos } \\
\text { econômicos }\end{array}$ & $\begin{array}{c}\text { Total dos } \\
\text { segmentos } \\
\text { econômicos }\end{array}$ \\
\hline 2010 & 46.616 & 2.757 .546 & 2.804 .162 \\
Proporção (\%) & 1,7 & 98,3 & 100,0 \\
2011 & 50.313 & 2.870 .276 & 2.920 .589 \\
Proporção (\%) & 1,7 & 98,3 & 100,0 \\
Variação & 107,9 & 104,1 & 104,2 \\
\hline
\end{tabular}

Fonte: Tabulação Observatório Unilasalle: Trabalho, Gestão e Políticas Públicas a partir dos dados do MTE/PDET/RAIS.

$\mathrm{Na}$ tabela 1 estão dispostos as quantidades de vínculos profissionais no Estado do Rio Grande do Sul, neste trabalho assumida como igual a quantidade de trabalhadores na indústria criativa, nos demais segmentos econômicos e no total das atividades econômicas. $\mathrm{Na}$ mesma tabela pode-se perceber a proporção, em percentual, que cada segmento produtivo ocupa no conjunto das atividades. Finalmente evidencia-se variação calculada por meio do índice de base 100 do ano de 2010 para 2011.

Ao analisar a tabela 1 pode-se perceber que nos anos de 2010 e 2011 a Cadeia da Indústria Criativa é responsável por menos de $2 \%$ dos postos de trabalho no mercado de trabalho formal no estado do Rio Grande do Sul. Também se verifica o crescimento de 107,9 no indicador de base 100 calculado, superior ao crescimento total das atividades econômicas que foi de 104,2 e das outras atividades econômicas que apresentou uma variação de 104,1. Evidenciase, apesar da análise ser de apenas dois anos, a existência de uma dinâmica na Indústria Criativa diversa das outras atividades econômicas.

A tabela 2 apresenta a quantidade de vínculos profissionais por segmento e no conjunto e, também, a proporção de cada segmento no total da Indústria Criativa no Rio Grande do Sul, nos anos de 2010 e 2011.

Observando a tabela 2 verifica-se que nos anos de 2010 e 2011 o setor da Arquitetura \& Engenharia assume o primeiro lugar na absorção de postos de trabalhos na Indústria Criativa no estado, com 10.690 $(22,9 \%)$ e $11.516(22,9)$ respectivamente, apresentado um crescimento absoluto de 
postos de trabalho, a segunda atividade que mais emprega é o Design com 7.861 (16,9\%) e $8.673(17,2 \%)$ que também apresenta crescimento de postos de trabalho. O terceiro é a atividade de Software, Computação \&Telecom que passa de $6.438(13,8 \%)$ para $7.249(14,4 \%)$ nos anos estudados.

Tabela 2 - Quantidade e proporção de vínculos profissionais por segmento e pelo conjunto da Indústria Criativa no Rio Grande do Sul, nos anos de 2010 e 2011.

\begin{tabular}{|c|c|c|c|c|}
\hline & 2010 & Prop. & 2011 & Prop. \\
\hline $\begin{array}{l}\text { Arquitetura \& } \\
\text { Engenharia }\end{array}$ & 10.690 & $22,9 \%$ & 11.516 & $22,9 \%$ \\
\hline Artes & 1.642 & $3,5 \%$ & 1.709 & $3,4 \%$ \\
\hline Artes Cênicas & 292 & $0,6 \%$ & 295 & $0,6 \%$ \\
\hline Biotecnologia & 711 & $1,5 \%$ & 846 & $1,7 \%$ \\
\hline Design & 7.861 & $16,9 \%$ & 8.673 & $17,2 \%$ \\
\hline $\begin{array}{l}\text { Expressões } \\
\text { Culturais }\end{array}$ & 376 & $0,8 \%$ & 466 & $0,9 \%$ \\
\hline Filme \& Vídeo & 1.203 & $2,6 \%$ & 1.129 & $2,2 \%$ \\
\hline $\begin{array}{l}\text { Mercado } \\
\text { Editorial }\end{array}$ & 3.659 & $7,8 \%$ & 4.003 & $8,0 \%$ \\
\hline Moda & 4.134 & $8,9 \%$ & 3.991 & $7,9 \%$ \\
\hline Música & 602 & $1,3 \%$ & 649 & $1,3 \%$ \\
\hline $\begin{array}{l}\text { Pesquisa \& } \\
\text { Desenvolvimento }\end{array}$ & 1.404 & $3,0 \%$ & 1.646 & $3,3 \%$ \\
\hline Publicidade & 4.726 & $10,1 \%$ & 5.227 & $10,4 \%$ \\
\hline $\begin{array}{l}\text { Software, } \\
\text { Computação } \\
\text { \&Telecom }\end{array}$ & 6.438 & $13,8 \%$ & 7.249 & $14,4 \%$ \\
\hline $\begin{array}{l}\text { Televisão \& } \\
\text { Rádio }\end{array}$ & 2.878 & $6,2 \%$ & 2.914 & $5,8 \%$ \\
\hline $\begin{array}{l}\text { Total da } \\
\text { Indústria } \\
\text { Criativa }\end{array}$ & 46.616 & $100,0 \%$ & 50.313 & $100,0 \%$ \\
\hline
\end{tabular}

Fonte: Tabulação Observatório Unilasalle:
Trabalho, Gestão e Políticas Públicas a partir dos dados do MTE/PDET/RAIS.

O segmento de Filme \& Vídeo e de Moda tem tanto a sua participação relativa diminuída como também ocorre uma queda em termos absolutos como se pode melhor visualizar na Figura 1 apresentado na sequência.
Considerando a classificação da UNCTAD a qual denominou de núcleo da indústria os segmentos de Expressões Culturais, Artes Cênicas, Artes Visuais, Música, Filme \& Vídeo, TV \& Rádio, Mercado Editorial, Software \& Computação, Arquitetura, Design, Moda e Publicidade, o Estado apresentou entre os três primeiros segmentos em empregos da indústria criativa, a: arquitetura e engenharia, design e Software, Computação \&Telecom. Juntos estes contabilizam 50\% dos quase 50.000 empregos nos diferentes segmentos. Estes segmentos exigem um maior grau de escolaridade, sobretudo aqueles ligados ao TI que é o caso do software, computação e telecomunicações.

A Figura 1 mostra a variação na quantidade de vínculos profissionais por segmento e no conjunto da Indústria Criativa no Rio Grande do Sul, nos anos de 2010 e 2011, tendo como base 100 o ano de 2010.

Figura 1 - Variação na quantidade de vínculos profissionais por segmento da Indústria Criativa no Rio Grande do Sul, nos anos de 2010 e 2011 (Base 100 = 2010)

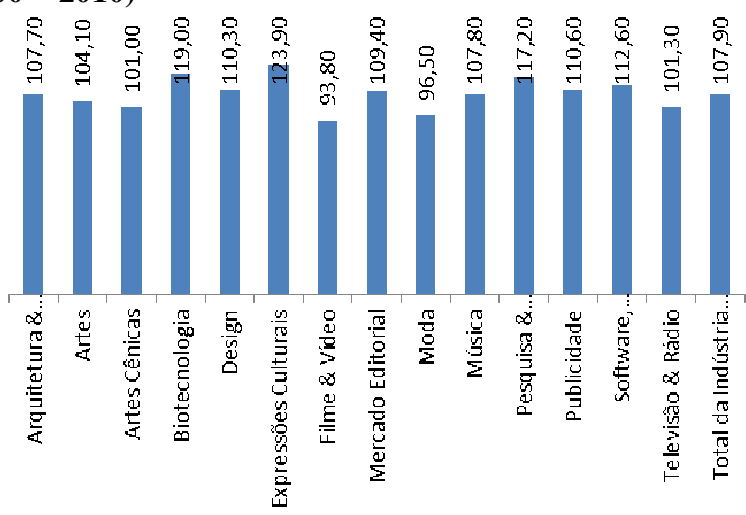

Fonte: Tabulação Observatório Unilasalle: Trabalho, Gestão e Políticas Públicas a partir dos dados do MTE/PDET/RAIS. 
Na Figura 1 observa-se que o conjunto da Indústria Criativa no estado cresceu em 107,9 de acordo com o indicador de base 100 calculado, o que significa $7,9 \%$. O setor que mais cresceu foi o das Expressões Culturais com o índice de base 100 calculado em 123,9, seguido pelo de Biotecnologia com 119,0. Pesquisa \& Desenvolvimento foi o terceiro setor como 117,2. Os dois setores que encolherem de 2010 para 2011 foram a Moda e Filme \& Vídeo com 4,5\% e $6,8 \%$ respectivamente. $\mathrm{Na}$ próxima ilustração é apresentado o valor da remuneração por segmento da Indústria Criativa.

Tabela 3 - Valor da remuneração média, em $R$ \$ 1,00, e proporção dos vínculos profissionais por segmento da Indústria Criativa no Rio Grande do Sul, nos anos de 2010 e 2011.

\begin{tabular}{|c|c|c|c|c|}
\hline & 2010 & $\%$ & 2011 & $\%$ \\
\hline $\begin{array}{l}\text { Arquitetura \& } \\
\text { Engenharia }\end{array}$ & $6.399,80$ & 2,52 & $6.685,12$ & 2,57 \\
\hline Artes & $1.882,20$ & 0,04 & $2.062,74$ & 0,10 \\
\hline Artes Cênicas & $2.548,78$ & 0,40 & $2.216,39$ & 0,18 \\
\hline Biotecnologia & $3.608,08$ & 0,99 & $3.660,25$ & 0,96 \\
\hline Design & $2.293,91$ & 0,26 & $2.363,87$ & 0,26 \\
\hline $\begin{array}{l}\text { Expressões } \\
\text { Culturais }\end{array}$ & 869,37 & $(0,52)$ & 941,78 & $(0,50)$ \\
\hline Filme \& Vídeo & $1.603,46$ & $(0,12)$ & $1.668,35$ & $(0,11)$ \\
\hline $\begin{array}{l}\text { Mercado } \\
\text { Editorial }\end{array}$ & $2.367,22$ & 0,30 & $2.363,99$ & 0,26 \\
\hline Moda & $1.729,99$ & $(0,05)$ & $1.793,19$ & $(0,04)$ \\
\hline Música & $1.518,35$ & $(0,16)$ & $1.586,71$ & $(0,15)$ \\
\hline $\begin{array}{l}\text { Pesquisa \& } \\
\text { Desenvolvimento }\end{array}$ & $7.195,35$ & 2,96 & $7.137,96$ & 2,81 \\
\hline Publicidade & $3.711,89$ & 1,04 & $3.700,64$ & 0,98 \\
\hline $\begin{array}{l}\text { Software, } \\
\text { Computação } \\
\text { \&Telecom }\end{array}$ & $3.591,14$ & 0,98 & $3.769,82$ & 1,01 \\
\hline $\begin{array}{l}\text { Televisão \& } \\
\text { Rádio }\end{array}$ & $1.319,82$ & $(0,27)$ & $1.341,33$ & $(0,28)$ \\
\hline $\begin{array}{l}\text { Conjunto dos } \\
\text { segmentos } \\
\text { econômicos }\end{array}$ & $1.816,87$ & - & $1.871,22$ & \\
\hline
\end{tabular}

Fonte: Tabulação Observatório Unilasalle: Trabalho, Gestão e Políticas Públicas a partir dos dados do MTE/PDET/RAIS.
Nota: Os valores estão constantes em Valores corrigidos para 01/02/2013 pelo IGP-DI.

$\mathrm{Na}$ tabela 3 pode-se perceber o valor da remuneração média dos vínculos profissionais por segmento da Indústria Criativa no Rio Grande do Sul, nos anos de 2010 e 2011, bem como a remuneração média de todos os segmentos econômicos. Evidencia-se ainda a proporção da renda de cada segmento criativo sobre o conjunto dos segmentos econômicos.

Nota-se na tabela 3 que a remuneração média no conjunto dos segmentos econômicos foi em torno de 1.800,00 nos anos de $2010 \mathrm{e}$ 2011. De 2010 para 2011 houve um crescimento de $3 \%$ como se pode verificar na Figura 2 valor calculado a partir do númeroíndice de base 100. Na indústria criativa o segmento de Arquitetura \& Engenharia é o que se destaca, ganhando em torno de 2,5 vezes proporcionalmente mais do que o conjunto dos segmentos econômicos. Seguido por Pesquisa e Desenvolvimento com 2,96 (2010) e 2,81 (2011) e por Publicidade com 1,04 (2010), no ano de 2011 o segmento de Software, Computação \&Telecom remunera 1,01 mais do que o conjunto dos setores econômicos. Chama a atenção os setores de Expressões Culturais, Filme \& Vídeo, Moda, Música e Televisão \& Rádio onde a remuneração é menor que a média do geral.

Assim, estes resultados, sobretudo o obtido pelo segmento de arquitetura e engenharia refletem os investimentos 
realizados em educação, pois um dos motivos para tal é a expiração de maior renda no futuro. O mesmo pode-se dizer de outros segmentos que exigem uma maior qualificação como são exemplos: Software, Computação \&Telecom.

Quando o olhar busca o comportamento da variação dos salários no segmento criativo, percebe-se na Figura 2 outra realidade.

Figura 2 - Variação da remuneração média dos vínculos profissionais por segmento da Indústria Criativa no Rio Grande do Sul, nos anos de 2010 e 2011.

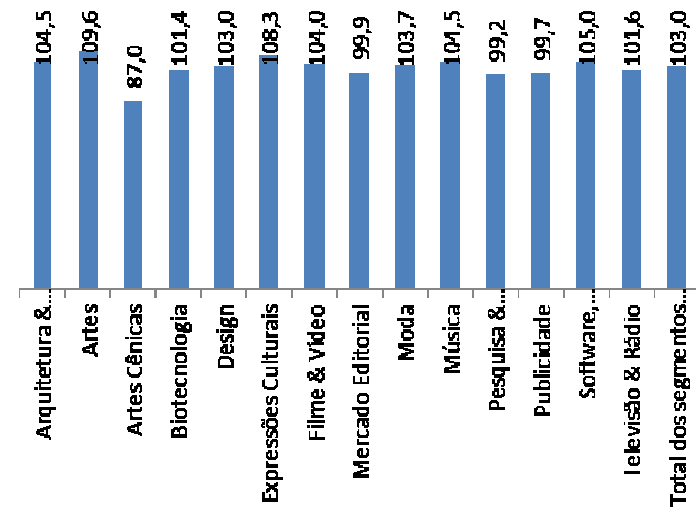

Fonte: Tabulação Observatório Unilasalle: Trabalho, Gestão e Políticas Públicas a partir dos dados do MTE/PDET/RAIS.

É no setor de Artes onde ocorre a maior variação nos salários com 109,9 calculados por meio do número-índice de base 100, seguido pelo setor de Expressões Culturais. Percebe-se que os segmentos de Publicidade, Pesquisa \& Desenvolvimento, Mercado Editorial, e Artes Cênicas apresentam redução real na remuneração, alguns discretos com 01,\% e outros mais acentuados com $13 \%$ como é o caso das Artes Cênicas. Estas alterações podem decorrer de dois fatores básicos: variações na demanda ou na oferta de mão de obra, ou uma valorização da atividade profissional em si já que muitas destas não podem ser "moldadas em bancos escolares de ensino superior", mas em decorrência do conhecimento, experiência profissional e do espírito intrínseco da "criatividade do artista".

\section{Considerações Finais}

As definições sobre indústrias ligadas às atividades culturais são mais ou menos amplas dependendo da natureza dos insumos, do foco da produção, do objeto, entre outros. Estas diferenças levam a segmentos diferenciados: enquanto definições mais recentes abrangem a Propaganda, Arquitetura, Design, Software interativo, como setores criativos, outras definições, mais tradicionais, consideram apenas Museus e galerias, Artes visuais e artesanato, Educação de artes, Broadcasting e filmes, Música, Artes performáticas, Literatura, Livrarias. Independente destas diferenças, o elo entre eles é a importância social e econômica destas atividades.

Economicamente, o trabalho ou vínculo empregatício é um dos indicadores de prosperidade regional. Assim, quanto maior o número de pessoas trabalhando e quanto maior for a escolaridade destas pessoas maior será a produtividade das mesmas.

Os segmentos da indústria criativa têm como insumo a criatividade e a formação 
profissional. No Rio Grande do Sul, mediante a análise dos dados observou-se que estes segmentos criativos ainda apresentam pouca relevância em termos de participação ocupacional, mas sobressaem-se a arquitetura e engenharia e a produção de softwares, computação e outros segmentos de TI. O primeiro caso talvez seja um reflexo dos programas governamentais como PAC e Minha Casa Minha Vida, entre outros, o que demanda uma maior formação nestas áreas. Quanto ao segundo, o crescimento da área de TI deriva da forte expansão mundial de todas as atividades ligadas à informática o que exige um maior número de pessoas habilitadas a tal exercício.

Quanto à remuneração a maior parte dos segmentos criativos teve uma variação média superior ao conjunto de todos os produtivos no Estado, o que mostra a importância crescente e a valorização da formação profissional e escolar destes indivíduos.

\section{Referências}

BRASIL. MINISTÉRIO DO TRABALHO E EMPREGO (MTE). Bases Estatísticas RAIS / CAGED - Acesso Online. Disponível em: $<$ http://sgt.caged.gov.br/index.asp $>$. Acesso em: jan. 2012

BRITISH COUNCIL. Creative and Cultural. Mapping the creative industries: a toolkit. London, 2010.60p. Creative and Cultural Economy series/ 2 .

FLORIDA, Richard. The rise of the creative class. New York: Basic Books, 2002.
HARTLEY, J (ed). Creative Industries. London: Blackwell Publishing, 2005

HENRY, Colette; BRUIN, Anne de (ed). Entrepreneurship and the creative economy: Process, practice and policy. Cheltenham: Edward Elgar Publishing Limited, 2011.

SANCHO, José Ramón L.; GRACIA, María Isabel G.; PRIETO, José Luis Z. Cultura y Economía. Madrid, Datautor, 2005.

UNITED NATIONS EDUCATIONAL SCIENTIFC AND CULTURAL ORGANIZATION - UNESCO.

Understanding creative industries. Cultural statistics for public-policy making. Disponível em: http://portal.unesco.org/pv_obj_cache/pv_obj _id_7D7822788289E0813D7CE385533915A 9E27A0100/filename/cultural_stat_EN.pdf. Acessado em: jan. 2013.

UNITED NATIONS CONFERENCE ON TRADE AND DEVELOPMENT UNCTAD. Creative Economy. Report 2008. Geneva; New York: UNCTAD; UNDP, 2008, p. 9-16. Disponível em: http://www.unctad.org/Templates/WebFlyer.a sp?intItemID $=5109 \&$ lang=1. Acessado em: Nov. 2011. 